\title{
Münchausen syndrome - a question of medical ethics?
}

\author{
Daniela Pacurar ${ }^{1,2}$, Gabriela Lesanu ${ }^{1,2}$, Anca Popescu' ${ }^{1}$ Irina Dijmarescu' ${ }^{1}$, \\ Dumitru Oraseanu ${ }^{1,2}$ \\ ${ }^{1}$ Pediatrics Clinic, "Grigore Alexandrescu" Clinical Emergency Hospital for Children, Bucharest, Romania \\ 2"Carol Davila" University of Medicine and Pharmacy, Bucharest, Romania
}

\begin{abstract}
"Factitious disorder" or "unnatural, artificial, fake disorders" as Münchausen syndrome (MS) and Münchausen syndrome by proxy (MSBP) represent severe mental disorders in which a person tries to convince those around him/her that he/she or the person depending on him/her is sick, without the purpose of obtaining benefits.

Patients with disorders such as MS or MSBP may arise a series of controversies and appeals from the simple question of patient status to confidentiality issues, privacy, medical malpractice or participation and involving of the medical team at the suffering of the patient. Recognition of the phenomenon of simulation depends heavily on experience of the physician, but the existence of elements of guidance and personality traits of patients or parents are important.

Many issues of ethics and medical deontology arise in diagnosis, evolution and treatment of these syndromes, many becoming subject to medical or legal disputes. The problem is more delicate and involves many consequences in terms of child protection in MSBP, considered the only form of lethal, highly complex mistreatment and abuse. Ethical, medical and ethics issues are different in the two types of diseases, but medical staff involvement and participation in perpetuation of the symptomatology is a common character, much debated. Despite the controversy, many of these issues remain unresolved and there are no clear guidelines so doctors can give an appropriate response.
\end{abstract}

Keywords: Münchausen by proxy, child, ethics

The "Münchausen Syndrome" (MS), a term introduced in 1951 by Richard Asher, as well as the Münchausen Syndrome by Proxy (MSBP), as described in 1977 by Meadow, are comprised today in the "Factitious disorders" chapter, as a free translation - an "unnatural, artificial, counterfeit disorders" representing severe mental disorders, categorized in the Diagnostic and Statistical Manual of Mental Disorders, Fifth Edition, code: 300 (DSM5) and in OMS - International Statistical Classification of Diseases, 10th Revision, F68 code (ICD10). They are divided into 2 categories (1-3).

"Factitious Disorder Imposed on Self Author" or Münchausen Syndrome (MS) is a severe mental disorder in which a person tries to convince those around him/her that he/she is sick, aims to be sick, he/she hurts himself/herself, falsifies data, documents and medical tests in order to receive treatment (2-4).
"Factitious disorder imposed on another", also known as Münchausen Syndrome by Proxy (MSBP), is a serious mental disorder in which someone "fabricates" a disease to another person, then asks for medical intervention. More often the parents are involved, falsifying the child's medical history, this fact being considered a potentially lethal form of child abuse, often misunderstood and undetected (4).

To these 2 categories was added, since 2000, a third category of "Factitious Disorders" called Münchausen By Internet, not yet categorized in the DSM-5 (5).

"Factitious disorder" does not mean to falsify medical data for the purpose of obtaining benefits (financial or administrative). The symptoms expressed by the mother as belonging to her child, do not aim to obtain personal advantages, but are fuelled by the mother's desire to be awarded the 
role of "hero" and to be recognized as the person who provides the utmost care for their children. There have been reports that the victims of people suffering from MSBP might develop MS or might continue to transmit the MSBP "pattern" to their children (4).

Such "mysterious" diseases are difficult to treat, the medical and psychological therapy being very important in preventing "self-flagellation". So far, about 30 cases of MS were described in teenagers or children older than 12 years old, most often these cases remaining undiscovered and rarely diagnosed (6).

\section{Legal and ethical issues in MS}

Some of the ethical or legal issues related to "Factitious disorders", either MS or MSBP may become the subject of legal proceedings or public debates. Despite the controversy, many of these issues remain unresolved and there are no clear guidelines so that the doctor may offer an adequate response in such situations (7). Numerous issues of medical ethics and deontology arise during diagnosis, during the evolution and treatment of such syndromes, and we are trying to bring them to the public's attention. The problem is much more delicate and involves consequences in terms of child protection in the case of MSBP, considered as the only lethal and highly complex form of abuse currently known. The MSBP syndrome is a public health tragedy.

\section{Accuracy of diagnosis}

Recognising the dissimulation phenomenon depends a lot on the physician's experience, as well as on his/her speciality or concerns. For example, neurologists often prefer the diagnosis of hysteria rather than a factitious disorder diagnosis, and this fact is perhaps due to the social impact that such disorder might cause (8). Using different clinical presentation patterns, the patients must be categorized by the medical professionals in one of the two categories: a person with abnormal behavior or a truly sick person, without ignoring the contribution of personal or social motivation factors. Therefore, we face two problems.

The first problem is the faulty diagnosis of the actual disease (9). This situation, that must be necessarily avoided, consists of the fact that the physician, in his/her hastes to demonstrate the presence of a "factitious disorder" syndrome, might cause an erroneous diagnosis of a real organic disorder. The patient's symptoms may be attributed to a factitious disorder only after a careful consideration and investigation; therefore, a patient must not be diagnosed with MS based only on certain unpleasant, unnatural or unusual psychological or behavior features.

MS may be suspected in a patient with: a long medical history and inconsistencies between the history of its claimed disease and the objective medical data, acute medical problems apparently convincing, but atypical, with vague and inconsistent symptoms, frequent hospitalizations, medical conditions with an unfavorable outcome for no apparent reason, the patient's desire to be subjected to frequent medical assessments, even to risky surgeries, with extensive medical knowledge - "by the book", an inconsistent attitude - from extremely cooperative to extremely vague in terms of his/her medical history, a mood and emotions more favorable and optimistic than would be justified by the patient's disorder $(4,10,11)$. Frequently, the patient comes in to benefit from healthcare services when his/her previous medical records are difficult to access or when the known or experienced medical personnel is missing (10). They are examined in the emergency rooms of hospitals during busy on-call shifts, they request several consultations, even using false identities, they have few visitors from the time of their admission, and they are reluctant to allow the medical personnel to talk to their families, friends or other physicians. Their conflicts with the medical personnel occur when their requests related to medication, diagnosis and medical assessments are not met $(3,12)$. There should be evaluated the elements of the clinical examination that may suggest the presence of MS: multiple surgical scars, signs of self-mutilation, irrelevant signs during the neurological examination, the absence of signs of dehydration in patients with frequent diarrhea and vomiting, symptoms that seem to worsen during the clinical examination compared with the moment of contact with the patient's family.

Most often, during the first medical consultations, such symptoms are interpreted by the physicians as belonging to a real somatic disorder with an atypical presentation, or to a rare disease, and these patients, who became experts in fabricating their symptoms, represent diagnostic challenges for their physicians. Thus, for the medical personnel, it becomes equally difficult to diagnose or to confirm the absence of a disease $(10,11)$. It is very difficult to diagnose MS due to the lack of patient's honesty, of complex, unclear symptoms, in a permanent dynamic. It is extremely important, since the moment of arising suspicions, as well as for supporting the 
diagnosis, to take a detailed medical history, in a careful manner, observing the correct chronology and inventory of all medical records.

Potential abuses, frustrations or traumas suffered during childhood must be correctly identified (13) It is necessary to diagnose psychiatric disorders (anxiety syndrome, personality disorder) and the psychological and/or psychiatric consult is mandatory $(3,10,11)$.

The ethical and legal issues in the cases of MSBP or MS are related to medical malpractice liability due to the lack of a diagnosis for a real disease and for cataloguing it as MS or MSBP. In such cases, the medical personnel is put in a difficult situation by the defense, even when the patient was seen harming itself. The standard claim in such cases is that the initial disease was real, but it was incorrectly diagnosed and treated, so that the patient is currently disfigured or has permanent disabilities. Regardless of the evidence, the judges and juries tend to consider MS or MSBP as being unlikely and not credible, and they assume that the patient has a mental illness. The presence of a wealthy patient, with an appropriate behavior and a neat appearance in the courtroom might tip the scales in favor of the patient (14).

The second problem is the faulty diagnosis of the factitious disorder (15). In this scenario, a patient with MS or MSBP sues the medical personnel and the medical institutions for their failure to detect that the disease for which he/she was treated is false. The claim is that, as a result of such failure and mistakes, all treatments were administered improperly, the iatrogenic effects were completely unjustified and the physician violated the medical treatment guidelines in accordance with the diagnosis.

Another challenge in factitious disorders syndromes is the possibility that physicians might be involved as a witness or expert and they should be able to help a jury discern real somatic disorders from deception or factitious disorder syndromes.

\section{Real patients or not?}

A strong association exists between the human sickness behavior in some patients and the potential advantages or benefits that society grants to people with disabilities. "The role of a sick person is a partly legitimate and conditioned status that may be desired due to the potential social gains and advantages" (16).

It was noted that "despite reducing diseases pathologically speaking, and improving the physi- cians' healing abilities, the number of sick people is increasing" (17). In addition, our society more easily accepts the idea of a physical illness than that of a behavioral or emotional disorder or "a lack of capacity to adapt to living conditions" (17).

The first issue is the degree of voluntary deception/lying in "factitious disorders". A second issue is related to the difficulty of recognizing the concept of medical deception on the part of many physicians who remain reticent and distrustful to the possibility that the patient would behave in a deceitful manner in order to influence their medical opinion $(18,19)$. Another important aspect concerns the question of whether people with "factitious disorders" are actually patients, therefore, if they have the right to treatment and to receive medical documents from physicians or hospitals. The American Medical Association (AMA) and other organizations and experts believe that the patient is a person in need of care from the medical personnel and they establish with him/her a relationship based on trust, morality, responsibility and collaboration in order to heal the patient and remove his/her pain $(20,21)$.

Strictly considering this definition, the professional medical associations and the patients' associations believe that a person who tries to simulate an MS or MSBP type disorder should not fall into this category, therefore that patient should not receive medical care and treatment.

\section{The physician's responsibility}

An important issue is related to the responsibility of the physician who discovers a patient or a person who is simulating his/her disease. The medical records are confidential documents emanating from the physician-patient relationship and should not be communicated to third parties without the written consent of the patient, unless the information is required by law or the disclosure protects the welfare of the individual or of the society (20). Some patients categorically deny their physician the permission to communicate with other health care professionals or even with the patient's family about his/her health condition (22). A proposed solution in such situations is to use statements like "The patient forbade me to comment on the fact that he/she would have an MS or MSBP-like disorder", thus tacitly encouraging others to read between the lines (22). Another solution to the problem relies on the idea of dishonesty on the part of the patient. The physician-patient relationship, which establishes the right to confidentiality, provides that both the physician and the patient must 
perform their roles in good faith, strictly observing the truth, so that the physician may act for the welfare of the patient, regardless of the circumstances (20).

According to this view, the correct and ethical relationship between the physician and the patient ceases to exist when the patient engages in medical deception and lying (acting in bad faith). Thus, the physician may cease to comply with the patient's right to confidentiality, and he/she may share medical information with other specialists and with the patient's family in order to solve the case, for the benefit of the patient.

\section{Legal culpability of the patient}

A person who steals is considered guilty, is being prosecuted and sentenced to pay fines. A patient who simulates his/her disease is stealing the physicians' time and unnecessarily uses medical resources, but he/she will rarely be subjected to criminal prosecution and brought before a court of law (23). The legislation of several countries raises the question of a possible fraud and provides the payment of fines by the patient. The estimated costs caused by MS patients are $\$ 40$ million each year in US (24).

\section{Patient privacy}

An additional issue of ethics and legality is related to the patient's invasion of privacy in an attempt to discover the objects or means by which he/ she seeks to dissimulate a disease. The physician should respect and advocate for respecting the patient's privacy in all forms: physically, by respecting the privacy of his/her personal space, informationally, involving his/her personal data, decisionally, by respecting his/her personal choices and relationally, concerning his/her family or other personal relationships (20). Privacy is not absolute and must be decided and judged depending on the patient's needs and the resources of the medical units; however, patients should be informed about possible privacy issues (24).

The patient's trust and his/her consent to search his/her personal belongings must be earned, never letting him/her suspect that the medical personnel is aware of the falsity of his/her disease. The patient may insist that he/she has nothing to hide and may accept the search of his/her personal belongings. In some hospitals, in many countries, searching the patient upon admission is mandatory $(4,22)$.

Video coverage, patient wards included, using hidden cameras in order to detect patients with fac- titious disorders, is very controversial. Using cameras for monitoring patients is not considered a violation of their privacy if they are commonly used for monitoring certain services (e.g. intensive care units), but applying this method only for certain patients becomes a problem The pros and cons are debating the issue of the existence of patient's privacy in the hospital, but most voices are supporting the idea that hospital wards cannot provide privacy, and video surveillance is particularly useful in proving cases of abuse and MSBP $(25,26)$.

The legal advisors should meet with the medical team whenever such a decision for video surveillance must be taken, and the recommendation is that hospitals should have clear procedures for such situations.

In our country, such legal issues related to "factitious disorder" syndromes are not yet considered with the same acuity as in other countries, on one hand because of reluctance and mistrust of physicians over the possibility of patients mimicking certain diseases, on the other hand because of physicians' inexperience in detection and assessment of such patients and, last but not least, due to a lack of legislative knowledge of both physicians and patients, and the absence of legislative codes to regulate such situations.

\section{Confidentiality and informing the patient}

Another ethical issue is related to the legality of registering the patients with MS in patient registers that are to be made available to medical institutions both nationally and internationally, and to be used for identifying people with MS who reach medical services in several medical centers. For the medical personnel, such registers are useful, but US law considers them as a violation of the confidentiality of the patient's medical condition (27). Advocates for patients' rights are raising the question that people placed on these lists might receive inadequate medical care when they do have a real health problem, considering their history of multiple spurious claims. Another concern is that such lists could include individuals just for the simple reason that they are uncooperative or because the medical professionals could not establish a diagnosis. The supporters of establishing such registers have as an argument the fact that the patients will be helped because they will no longer be subjected to unnecessary and painful tests, procedures and treatments.

\section{Legal and ethical issues of MSBP}

In many states, the law ambiguously takes this syndrome into consideration, as well as the guilt of 
the accused abuser - who is affected by this pathology - towards the victim.

In Romania, this ambiguity was resolved by: Government Decision no. 49 of January 19, 2011, published in the Official Journal, updating the Law no. $217 / 2003$ on preventing and fighting (combating) domestic violence. "MSBP is the artificial creation of a child's illness by the parent; the illness is induced by voluntarily administering drugs or substances or by supporting the existence of symptoms suffered by the child that have never been confirmed by specialists. In both cases, the parents ask the physicians for numerous medical or surgical investigations, repeatedly victimizing their child. Any functional sign can be invoked by the parents in order to obtain painful and intrusive investigations and procedures for their child." (28). Also, it should be noted that, until recently, the judges and jurors were often distrustful about the existence of this form of abuse, being influenced by the "scholarly" pleadings made by the parents' attorneys (19).

MSBP must be seen as a life-threatening condition associated with a particular psychotic behavior and with potential iatrogenic complications (10).

\section{Justifying reasons for MSBP}

Many and various reasons for MSBP have been tried, from the point of view of the perpetratorabuser parent who is falsifying his/her child's illness, and all include (10, 29-31).

- Gaining sympathy, attention, respect and public recognition by masquerading as a devoted and loving mother, the only one able to save her child;

- Proving to others his/her high level of medical knowledge;

- The desire to prove to himself/herself, by deceiving the medical experts and by manipulating "important people" that he/she is truly in control of the situation;

- Getting rid of other responsibilities of daily life (such as education, work, housework), by being a devoted mother with a chronically sick child, gaining the image of a neglected wife or receiving help and support from other family members;

- Maintaining his/her own image of a person who "does good deeds", as well as interesting and important things;

- Participating in a social life, being part of the "hospital family", participating in social or charitable activities within the various wards of the hospital, which seems more exciting than the ordinary life of being a member of a single family;

- Sometimes, as a secondary purpose, but not as the main motivational element of MSBP, there may be the purpose of getting special food, attracting the public's or media's attention, community support or financial assistance, obtaining donations;

- However, it is necessary to lie, and the child must suffer in order to permanently have the attention of others. Because of this image problem of the mother, if the first child gets too sick, becomes invalid or dies, she immediately transfers the disease to a sibling of the first child (32).

The ethical and legal issues associated with MSBP do not relate only to the individual adult perpetrator, in an isolated manner, but also to its relationship with the medical personnel and the consequences of the medical personnel's actions over the child, as a result of the distortion of the reality presented by the parent. Thus, a series of specific problems must be considered in the case of this medical condition.

\section{The parent perpetrator and the medical personnel: partners in child abuse?}

Much controversy and many questions are still present in the diagnosis of MSBP: the MSBP term should be attributed to the parent-perpetrator or to the abused child? This syndrome is a psychiatric or pediatric condition? Who should decide the diagnosis: a pediatrician or a psychiatrist? (33) Regardless of the answers to these questions, certainly MSBP is clearly distinct from any other form of ill-treatment through the active involvement of the health care personnel in causing morbidities (34). MSBP is a form of abuse and the medical system takes part, in many cases, to its emergence and its perpetuation. Can we conclude that the parent-perpetrator and the medical personnel are equally responsible for the child's morbidity? $(35,36)$. MSBP is a special "triangle" relationship which develops between the parent-perpetrator, the child victim and the medical personnel, based on the child's abuse and the parent's deceit, associated with the act of deceiving the physician regarding the impossibility of establishing the diagnosis or finding an effective treatment $(10,30,37)$.

Some mothers seem to have a special skill for being impostors, they are able to simulate a medical condition, as well as an unusual concern and 
care for their sick child. The dedicated medical personnel is professionally and intellectually stimulated by challenging and unsolved cases after multiple surgeries and medical investigations, and they will try to find unusual and rare diagnoses, therefore showing a great interest for these individuals, by allocating them more time and attention, both to the child and mother $(30,34)$.

This special mother-child-physician "triangle" is strongly influenced by the character of the adults involved. All parents exhibit a permanent need for medical attention regarding their children, thus, they are fabricating an illness for them. In all cases, the parents of MSBP victims will "choose" the physician, they will search with perseverance, from a consultation to another, and they will find "that" physician who will satisfy their personal need of assistance and attention (37).

In our society, abundant in medical litigation, in which the physician is easily accused of malpractice on all media channels, of lack of medical attention, of failure to provide emergency therapy, of carelessness for the sick patient, it is easier for the parents of MSBP victims to insist and to pressure the medical personnel to do more for their child. In this way, the health care professionals are contributing and are helping the victims' parents to torture their own children with endless medical procedures. When previous investigations, tests, procedures and medications are considered by the family to no avail or are denied, the parents-perpetrators will consider that the medical system is incompetent and unable to help their "poor" child and the suffering mother $(10,30)$.

Video surveillance coverage, with hidden cameras in patients' wards, is a method by which, in other countries, is made a distinction between the "fabricated" medical events and the real ones. However, installing video cameras in patients' wards raises important moral, legal and ethical issues related to data confidentiality and professional secrecy. But, in certain situations, these methods have been very useful in identifying child abusers $(25,26)$.

\section{The impact of MS or MSBP on the medical personnel}

This relationship between the parent-perpetrator and the physician may be extended to all categories of health care professionals who participate in the child care (nurses, caregivers), who often are more frequently or more extensively in contact with the abusers and their victims. Frequently, the parents of children with MSBP can be characterized as charming, polite, attentive people who accommodate well to the hospital's conditions, and they make friends with people from the medical team or with other relatives of other patients. As parents, they seem devoted, attentive and careful with their children, and they have an admirable behavior. However, they have a tremendous capacity to deflect and to fool the medical personnel, they are two-faced people: one loving face, of a perfect mother, and another face capable to manipulate, to lie and to falsify medical conditions (39).

Although most mothers of MSBP victims are quite the flatterers, they can become aggressive if they fear they will lose the attention of others, if they are threatened to be exposed and unmasked, or when the medical personnel has opposing views and does not consider that further tests are necessary $(35,39)$. These intense reactions of only one person are capable to differently attract the attention of the medical personnel, to convey opinions and contradictory feelings in connection with the mother and her family, thus compromising the medical team's work $(29,37)$.

\section{MSBP versus typical forms of child abuse}

The first distinctive feature of MSBP versus other physical types of child abuse is related to the degree of premeditation. Most forms of child abuse involve hitting the child as a form of punishment for various actions (crying, enuresis, dirtying his/ her clothes), while the abuse of MSBP seems to not be caused by the child $(10,30,36,39)$.

The two forms of abuse share some common characteristics:

- the child has a long medical history;

- the adult perpetrators/abusers become angry and hostile when confronted with their own behaviour $(37,41)$;

- the abusers do not accept responsibility for the child's health care;

- the child's health suddenly improves when he/she is separated from his/her family;

- the abusers may withdraw together with the child if they detect the medical personnel's suspicions.

The elements that distinguish the two forms of abuse are presented in Table $1(35,40,41)$.

\section{Patient's Therapy and Education}

The assessment should not be limited to the child involved and should also include his/her brothers and other family members. Psychotherapy 
TABLE 1. MSBP versus other physical types of child abuse

\begin{tabular}{|c|c|}
\hline $\begin{array}{l}\text { The typical form of child abuse } \\
\text { The abuser's 'pattern' } \\
\text { - } \quad \text { is the child's stepfather or the mother's boyfriend } \\
\text { - } \text { avoids seeking medical assistance } \\
\text { - } \quad \text { requests a rapid discharge } \\
\text { - has a typical behaviour: sullen, hostile, appears as he } \\
\text { is in jeopardy } \\
\text { - } \quad \text { the parent leaves the impression of being responsible, } \\
\text { but has a "do not mess with me" attitude } \\
\text { - he feels threatened by the medical personnel } \\
\text { - } \quad \text { avoids contact with the medical personnel } \\
\text { The victim's 'pattern' } \\
\text { - } \quad \text { shows specif c signs of abuse or neglect } \\
\text { - his/her medical history is unclear }\end{array}$ & $\begin{array}{l}\text { The MSBP abuse } \\
\text { The abuser's 'pattern' } \\
\text { - It's almost always the mother } \\
\text { - } \quad \text { Seeks permanent medical assistance } \\
\text { - She cannot accept that she has a healthy child and asks for other tests, } \\
\text { - } \quad \text { She impresses the medical personnel with her medical knowledge } \\
\text { - } \quad \text { She needs to be appreciated as a devoted mother } \\
\text { - She seeks the attention of the medical personnel } \\
\text { - She becomes involved in the activity of the ward where the child is } \\
\quad \text { hospitalized, in the family life of the medical personnel or of other } \\
\text { The victim's 'pattern' } \\
\text { - Shows vague symptoms } \\
\text { - An accurate medical history, specif cally "by the book" } \\
\text { - Often presents with an atypical disease }\end{array}$ \\
\hline
\end{tabular}

should be a therapeutic method that benefits the mother, the affected children and other family members.

The family requires a careful long-term monitoring, especially because of the danger of trying to resume the same type of behavior in a new location (30).

US law provides that if a MSBP type disorder is suspected, the physicians are obliged to inform the authorities: Child Protective Services, Social Services. The parent-abuser is confronted with the evidence, he/she will deny all accusations and will attempt a quick discharge of the child. Confronting the parent-abuser may lead, for a while, to the disappearance of the child's symptoms, but in most cases, the parents go to other medical units, in another city. The unpleasant element of the confrontation is the permanent damage to the physician-patient-family relationship and completely losing the child from observation (37).

In severe cases, the treatment and cure of MSBP are obtained only by separating the child from the parent - abuser ("a total parentectomy"). This en- sures the child's safety, and an immediate reversibility of all his/her symptoms. The separation of mother and child can be, at the same time, a new reason of stress, anxiety and emotional trauma for the child, who perceives the separation from his/her mother as a punishment, since in his/her vision she is being a protecting and caring mother who wants only his/her well-being and is concerned with his/ her health status. Criminal prosecution may be required.

\section{CONCLUSIONS}

The MS and MSBP represent an inexhaustible topic that is particularly interesting and should be known by the residents, from the earliest years of their medical education. Knowing about this syndrome is important in order to properly diagnose patients, which would lead to the establishment of a correct therapeutic plan in the shortest time, as well as to protect us from accusations of malpractice, since these individuals are both stubborn litigants and complainers.

\section{REFERENCES}

1. Asher R. Münchausen's Syndrome. Lancet. 1951; 1: 339-41.

2. American Psychiatric Association. Diagnostic and Statistical Manual of Mental Disorders. Fifth Edition. Arlington, VA: American Psychiatric Association; 2013: 324-6.

3. American Psychiatric Association. Diagnostic and Statistical Manual of Mental Disorders. Fifth Edition. Arlington, VA: AmericanPsychiatric Association; 2013: 324-6.

4. Pacurar D., Runcan M., Popescu A. et al. Münchausen Syndrome By Proxy - A Real Pediatric Problem? Romanian Journal Of Pediatrics. 2015; LXIV (3): 311-317

5. Werner J., Willis $\mathrm{O}$. Münchausen by internet: What drives people to fake an illness online? ABC Health \& Wellbeing. Available at: http:/l www.abc.net.au/news/health/2016-07-15/munchausen-by-internetwhat-drives-people-to-fake-an-illness. Updated 23 December 2016

6. Jaghab K., Skodnek K., Padder T. Münchausen's Syndrome and Other Factitious Disorders in Children. Case Series and Literature Review Psychiatry (Edgmont). 2006; 3(3): 46-55.

7. Amlani A., Grewal G.S., Feldman M.D. Malingering by Proxy: A Literature Review and Current Perspectives. J Forensic Sci. 2016; 61(Suppl 1): S171-6.

8. Kanaan R.A., Wesselz S.C. Factitious disorders in neurology: an analyses of reported cases. Pszchosomatics. 2010; 51: 47-54

9. Bass C., Halligan P. Factitious disorders and malingering in relation to functional neurologic disorders. Handb Clin Neurol. 2017; 139: 509-520.

10. Criddle L. Monsters in the Closet: Münchausen Syndrome by Proxy. CriticalCareNurse. 2010; 30(6): 47-56 
11. Bass C., Halligan P. Factitious disorders and malingering: challenges for clinical assessment and management. Lancet. 2014; 383 (9926): 1422-32

12. Yates G.P., Feldman M.D. Factitious disorder: a systematic review of 455 cases in the professional literature. Gen Hosp Psychiatry. 2016; 41:20-8

13. Ferrara P., Vitelli O., Bottaro G. et al. Factitious disorders and Münchausen syndrome: the tip of the iceberg. J Child Health Care. 2013; 17(4):366-74.

14. Savino A., Fordtran J. Factitious disease - clinical lessons from case study at Baylor University Medical Center. Proc (Bayl univ Med Cent). 2006; 19 (3): 195-208

15. Yalndağ-Öztürk N., Erkek N., Şirinoğlu M.B. Think Again: First Do No Harm: A Case of Münchausen Syndrome by Proxy. Pediatr Emerg Care. 2015; 31(10):720-1

16. Vrij A. Detecting lies and deceit. Pitfalls and opportunities, 2nd Ed. Chichester Wilez, 2008

17. Wade D.T., Halligan P.W. Social role and long-term illness: is it the time to rehabilitate convalescence? Clin Rehabil. 2007; 21: 291-98

18. Jung B., Reidenberg M.M. Physicians being deceived. Pain Med. 2007; 8: 433-37

19. Bass C., Glaser D. Early recognition and management of fabricated or induced illness in children. Lancet. 2014; 383(9926):1412-21.

20. American Medical Association. AMA Principles of Medical Ethics: I,II,IV,VIII. Available at: https://www.ama-assn.org/about-us/ code-medical-ethics. Updated 2016

21. http://www.medicinenet.com/script/main/art.asp?articlekey=39154. Updated 2016

22. Kass F. Identification of persons with Münchausen's syndrome: Ethical problems. General Hospital Psychiatry Psychiatry, medicine and primary care. 1985; 7(3): 195-200

23. Feldman M. Playing Sick? Untangling the Web of Münchausen Syndrome, Münchausen by Proxy, Malingering, and Factitious Disorderes. Brunner Routledge, 2013

24. Jaghab K., Skodnek K., Padder T. Münchausen's Syndrome and Other Factitious Disorders in Children Case Series and Literature Review. Psychiatry (Edgmont). 2006; 3(3): 46-55.

25. Royal College of Paediatrics and Child Health. Fabricated or Induced Illness by Carers: A Practical Guide for Paediatricians. 2009

26. Children's Dept of Health. Safeguarding Children in Whom Illness is Fabricated or Induced; Supplementary guidance to Working Together to Safeguard Children Dept of Health. HM Government. 2008: 16-34
27. Dyer A., Feldman M. Factitious Disorder: Detection, Diagnosis, and Forensic Implications. Psychiatric Times. 2007. Available at: www. psychiatrictimes.com

28. Hotărârea nr. 49 din 19 ianuarie 2011, Monitorul Oficial

29. Fulton D.R. Early recognition of Münchausen syndrome by proxy. Crit Care Nurs Q. 2000; 23(2):35-42.

30. Schreier H.A. Münchausen by proxy. Curr Probl Pediatr Adolesc Health Care. 2004; 34(3): 126-143.

31. Sheridan M.S. The deceit continues: an updated literature review of Münchausen Syndrome by proxy. Child Abuse Negl. 2003; 27(4):431-451.

32. Morrell B., Tilley D.S. The role of nonperpetrating fathers in Münchausen syndrome by proxy: a review of the literature. J Pediatr Nurs. 2012; 27(4): 328-35.

33. Meadow R. Different interpretations of Münchausen syndrome by proxy. Child Abuse Negl. 2002; 26(5):501-508.

34. Chafetz M., Dufrene M. Malingering-by-proxy: Need for child protection and guidance for reporting. Child Abuse Negl. 2014; 38(11):1755-1765.

35. Stirling J. Beyond Münchausen syndrome by proxy: identification and treatment of child abuse in a medical setting. Pediatrics. 2007; 119(5): 1026-1030

36. Donald T., Jureidini J. Münchausen syndrome by proxy: child abuse in the medical system. Arch Pediatr Adolesc Med. 1996; 150(7):753-758

37. Fraher A. A toxic triangle of destructive leadership at Bristol Royal Infirmary: A study of organizational Münchausen syndrome by proxy. Leadership. 2016; 12(1) 34-52

38. Pasqualone G.A., Fitzgerald S.M. Münchausen by proxy syndrome: the forensic challenge of recognition, diagnosis, and reporting. Crit Care Nurs Q. 1999; 22(1):52-64

39. Flaherty E.G., Macmillan H.L. Committee On Child Abuse And Neglect. Caregiver-fabricated illness in a child: a manifestation of child maltreatment. Pediatrics. 2013; 132(3): 590-7

40. Galvin H.K., Newton A.W., Vandeven A.M. Update on Münchausen syndrome by proxy. Curr Opin Pediatr. 2005; 17(2):252-257

41. Rosenberg D. Muünchausen Syndrome by Proxy: medical diagnostic criteria. Child Abuse Negl. 2003; 27(4):421-430

Conflict of interest: none declared Financial support: none declared 